\title{
O DESENVOLVIMENTO DE AVANÇOS TECNOLÓGICOS E A ORGANIZAÇÃO BUROCRÁTICA TRANSFORMANDO A POLÍTICA DE EXTERMÍNIO DO HOLOCAUSTO
}

Maria Eduarda Valente ${ }^{1}$

\section{Resumo}

O Holocausto que aconteceu durante a Segunda Guerra Mundial ficou amplamente conhecido pelas atrocidades ocorridas, com a introdução de avanços tecnológicos e a organização burocrática que intensificaram a política de extermínio desse evento. O uso dos campos civis de concentração, a participação de empresas privadas, o papel dos perpetradores de maneira organizada, entre outros, possibilitaram a relação entre a tecnologia e a violência direta, colocando inovações como mecanismos de progresso. Desta forma, o presente artigo visa demonstrar a relação entre o uso da tecnologia e a organização burocrática, ambos mecanismos de uma sociedade moderna e inovadora, como facilitadores da aniquilação em massa, impactando de forma direta na política de extermínio. Com isso, o trabalho será fundamentado primeiro na tecnologia colocada como (não) neutra contrapondo ao que foi desenvolvido no genocídio judeu de forma inovadora incorporando valor; em seguida, a teoria do genocídio, que orienta e justifica a escolha desse caso em meio a práticas de conflitos de forma geral. Por fim, concluindo com os avanços tecnológicos desenvolvidos nos dias de hoje, que diferentemente do último século, são instrumentalizados de forma contrária à violência direta, mas voltado à prevenção e resposta às atrocidades.

Palavras chave: Avanços tecnológicos - Holocausto - Genocídio - Organização Burocracia.

\section{Abstract}

The Holocaust that took place during the Second World War became widely known for its occurred atrocities and the introduction of technological advances and bureaucratic organization intensified the extermination policy of this event.

\footnotetext{
1 Graduanda do oitavo período da Relações Internacionais no Instituto de Relações Internacionais da Pontifícia Universidade Católica do Rio de Janeiro. E-mail: mariaemmcv@outlook.com.
} 
The use of civilian concentration camps, the action of private companies, the role of perpetrators in an organized way, among others, made possible the relationship between technology and direct violence, placing innovations as mechanisms for progress. That given, the present article intends to demonstrate the relationship between the employment of technologies and bureaucratic organization, both instruments of the modern and innovative society, as facilitators of mass annihilation, which impacted in a direct way the extermination policy. Therefore, the work will be grounded first on a technological constructed as (not) neutral, contrasting to was developed in the Jewish genocide in an innovative way incorporating value; then, the genocide theory, by which the choice of this specific case is defined and justified in face of more general conflict practices in general. Finally, concluding with the technology developed nowadays, which, unlike the last century, is instrumentalized in a way contrary to direct violence, but aimed on preventing and responding to atrocities.

\section{Keywords: Technological Advances - Holocaust - Genocide - Organization - Bureaucratic.}

\section{Introdução}

O século $X X$ foi um importante marco para o progresso da modernidade, segundo Thomas Friedman (2005), no qual as novas tecnologias tiveram papel central, dado que são colocadas como transformadoras do espaço planetário. No território europeu, o desenvolvimento tecnológico com seu avanço e aprimoramento ocorreu por meio da infraestrutura, condições sociais e intelectuais da sociedade. A modificação desse espaço na forma pela qual a tecnologia fora colocada foi o mecanismo utilizado e aprimorado pelo regime autoritário nazista voltado para uma política de extermínio. Tendo em vista esse cenário, o foco do trabalho é na categoria do moderno, compreendendo a relação entre o Holocausto e as tecnologias, diante da utilização dessas para a manutenção da segurança de um povo.

O problema central do artigo se dá pelo uso e desenvolvimento da tecnologia alinhado a uma organização burocrática para fins de extermínio no caso do Holocausto. Como argumento, será colocado que a tecnologia inicialmente é neutra, mas na medida em que é demandada pelas exigências do agente ganha um novo valor (Katz, 2005). Para isso, na primeira seção o conceito 
de tecnologia dada como neutra é questionado no século $\mathrm{XX}$ diante de um contraexemplo: o genocídio judeu perpetrado pelas ações e ferramentas desenvolvidas pelos nazistas, ocorrido em nome da segurança do território europeu diante da ameaça judia à "raça pura ariana". Na segunda seção, pensar a própria definição de genocídio é importante, termo que foi cuidadosamente trabalhado por Raphael Lemkin², o qual veio a existir somente após 1944 com o Holocausto, acontecimento que fomentou os estudos do termo, o que relaciona e justifica o foco neste caso.

Desse modo, depois de definir esse conflito como genocida, a antropologia e a sociologia do Holocausto ganham espaço. Essa interdisciplinaridade alinha-se ao moderno na medida em que o caso teve a oportunidade de se desenvolver de maneira facilitada por ser uma época mais avançada e moderna. Na terceira seção, surge a participação de empresas privadas como a IBM e I.G. Farben que tiveram suas empresas alemães servindo ao governo nazista e trabalhando num projeto de extermínio, trazendo a dúvida se a participação dessas era consentida ou fora induzida.

Em seguida, o artigo irá apresentar a participação da sociedade nesse cenário, evidenciando o indivíduo e seus princípios ao agir diante de um extermínio, por meio de uma organização altamente burocrática. Como cientistas e estudiosos, que pensaram em formas de desenvolver a tecnologia e imbuíram o valor na ciência, orquestrando ferramentas cada vez mais elaboradas para conseguir uma aniquilação eficiente e em larga escala como incitado. Além dos perpetradores diretos do projeto nazista, alguns que antes de se inserirem na política de extermínio eram pessoas "normais", sem histórico de atrocidades, para exemplo será apresentado um deles com base no trabalho de campo feito ao antigo campo de concentração Sachsenhausen, localizado próximo a Berlim.

Por fim, a última seção será dedicada à tecnologia que tem sido desenvolvida nos dias atuais, voltada à prevenção e resposta às atrocidades, que se faz possível na medida em que dados tem sido gerados para identificar os fatores precedentes dos conflitos e evitar que novos aconteçam. Essa nova abordagem se opõe às práticas de instrumentalização da tecnologia no passado, quando houve o uso e desenvolvimento de inovações alinhados a uma organização burocrática para fins de extermínio no século XX. Ao invés disso, prioriza-se hoje o aproveitamento de ferramentas para a defesa dos direitos

\footnotetext{
2 Advogado polonês, de origem judaica, que criou o termo "genocídio" apontando os casos de massacre da época, "combinando a palavra grega geno-, que significa raça ou tribo, com a palavra latina -cídio, que quer dizer matar", após usarem palavras como "barbárie" e "vandalismo", que não impactaram da mesma forma (United States Holocaust Memoriam Museum, [s.d.]c)
} 
humanos, como a comunicação e coleta de dados de forma online para direcionar recursos e assistências a pessoas em situações de risco. Diante disso, indaga-se qual o espaço da modernidade, inicialmente colocada como o ambiente que possibilitou o desenvolvimento tecnológico, mas que no último século foi utilizada em uma política de extermínio.

Para isso, recorre-se a revisão de literatura do tema a partir de autores que envolvem a tecnologia, genocídio e modernidade. Eric Katz (2005) e Langdon Winner (1986) trabalham esse conceito da neutralidade da tecnologia colocada em questão. Em seguida, Adam Jones (2011) é o principal teórico sobre a definição de genocídio, em diálogo com Alexander Hinton (2002) e Martin Shaw (2010) que expandem o termo em sua interdisciplinaridade para a antropologia e sociologia. Zygmunt Bauman (1998) surge em seguida para entrelaçar a teoria de genocídio apresentada inicialmente ao conceito de modernidade e os avanços tecnológicos desenvolvidos no Holocausto, com seu principal argumento que a modernidade não se faz necessária, mas possui condições suficientes que permitam com que casos como o Holocausto aconteçam. Adiante, as empresas alemãs, Edwin Black (2002) posiciona o papel da subsidiária da IBM no contexto do Holocausto, além de Joseph Borkin (1978) e Robert Leventhal (1995) com a I.G. Farben. Em relação ao papel dos perpetradores, como mencionado será apresentado o trabalho de campo na Alemanha e por último Christopher Tuckwood (2004), posicionando as tecnologias atuais.

\section{Elucidando a tecnologia (não) livre de valor}

Inicialmente o desenvolvimento tecnológico possui uma neutralidade intrínseca e independente de valor, porém quando demandado pelo agente em um dado momento há objetivos e intenções que são vistos como obstáculos a isso, pelo fato das necessidades e exigências desse deixarem emergir o seu valor no emprego da tecnologia, como aponta o autor Katz (2005). Uma tecnologia que seja desenvolvida em tempos de genocídio inicialmente não é um problema, mas é preciso considerar quem está definindo a intencionalidade e direcionando de forma sociopolítica o progresso dessa ferramenta, pelo fato que isso pode trazer consequências fatais. Assim sendo, a presente seção será baseada na ideia da tecnologia dada como neutra até surgir intenções do agente que ao emprega-la impõe o seu valor:

Perhaps the oldest commonplace about the nature of technology is that technological artifacts are inherently neutral or value-free. Humans create technological objects for a 
specific range of purposes, but the actual use of the technology is subject to the intentions of the user. These intentions, of course, may be good or they may be evil, but whether good or evil, the technology itself is neutral: the technology has no purpose, no value of its own, except insofar as it meets the needs and requirements of the agent who employs the technology (Katz, 2005, p. 409).

A ideia de neutralidade é colocada no dilema da criação do objeto tecnológico por si só versus qual a utilização que se dará em seguida. O making é moralmente neutro, já o valor surge quando e por quem o objeto é demandado. Winner (1986) indica a tecnologia puramente como uma ferramenta a ser utilizada para qualquer propósito que o usuário tenha em mente. Cabe a profissionais tecnológicos, engenheiros e cientistas desenvolverem o objeto ou sistema de acordo com o demandado, o que causa involuntariamente a criação de um valor neste. O problema central aqui é como as tecnologias foram desenvolvidas por (e para) práticas autoritárias, como máquinas de tabulação que por si só eram neutras, mas que ao serem elaboradas para o fim ditado pelo agente adquirem o valor desse que as demandou.

Além disso, é possível ir além do uso dado às ferramentas tecnológicas: o autor aponta que por meio de uma tecnologia a sociedade pode ter suas atividades padrões ou instituições reestruturadas a fim de propiciar novas formas de organização (Winner, 1986). Podemos ilustrar esse entendimento a partir dos moldes alemães de perpetração do Holocausto, que, ao utilizar-se de ferramentas, como as desenvolvidas pelas subsidiárias alemãs ${ }^{3}$, modificaram sua organização política e burocrática, em volta do objetivo de um novo modelo de sociedade puramente ariano, dado como ideal e único.

Portanto, no século $X X$, a ideia popular de uma ciência livre de valor é questionada (Katz, 2005). Todas as iniciativas humanas, sejam ideias ou produtos criados, foram resultados de uma história e cultura ou subcultura, como raça, classe e gênero, que emergem no contexto do desenvolvimento tecnológico em questão. Posto isto, a tecnologia incorporou formas específicas de poder e autoridade nazista, seja por meio das ferramentas desenvolvidas ou da burocracia organizacional que se adaptou de maneira moderna para ordenar um grupo social. A organização nos campos de concentração no período nazista era intencional, e se intensificou com as ferramentas e artefatos desenvolvidos para o extermínio de indivíduos naquele espaço.

\footnotetext{
${ }^{3}$ Referência aos serviços prestados pela IBM e I.G. Farben, que serão dilucidados adiante.
} 
Por exemplo, o sistema ferroviário tem o transporte por si como independente, mas a sua utilização e seu sistema funcional quando determinado para o controle de um grupo foi baseado numa estrutura de poder. $O$ uso da tecnologia através desse transporte, que controlava as pessoas que seriam levadas aos espaços de extermínio demonstra um sistema estruturado para um objetivo definido. Portanto, a vida dessas pessoas fora alterada de acordo com a forma de operar dessa tecnologia, que deixa de ser neutra, para ser estruturada por uma organização política. Ou seja, um sistema tecnológico utilizado para resolver um problema ou política social: nesse caso, a aspiração de transportar as pessoas de determinada forma. Esse projeto de morte nazista é um exemplo de como ferramentas e sistemas não são moralmente ou politicamente neutros, mas alterados pelo agente que as demanda.

A neutralidade de projeto tecnológico se perde em outro exemplo: os engenheiros que projetaram os fornos da crematória dos campos de extermínio nazistas tiveram um propósito específico em mente quando desenvolveram. A empresa Topf and Sons, originária da Alemanha do século XIX, foi atuante no maquinário modificado para refletir aos objetivos de extermínio em massa em Auschwitz, como aponta Jean-Claude Pressac e Robert-Jan van Pelt (1998). De início, eram crematórios destinados a corpos que morrem de causas naturais, como doenças, má nutrição e velhice, porém, na época, tiveram outro propósito alinhado à Solução Final ${ }^{4}$. A empresa alterou de maneira inovadora os crematórios, tornando possível que fornos com múltiplas câmaras fossem estabelecidos para queimar os cadáveres de forma mais eficiente, já que nesse caso não seria mais necessário preservar a integridade das cinzas, como teria sido feito em um estabelecimento privado comercial de crematórios.

A combinação dos fornos do crematório com as câmaras de gás é acompanhada pelo uso do Zyklon-B, gás tóxico e mortal que foi utilizado pelos nazistas nos campos civis de concentração. A precaução da logística dos prisioneiros às câmaras fez com que a construção dessas, junto aos crematórios, fosse um projeto sigiloso de morte, em especial, para que as vítimas que fossem levadas vivas inalassem o gás e fossem queimadas fora da visão do resto do campo, o que geraria uma eficiência na incineração (Pressac \& Van Pelt, 1998). Ou seja, exemplo que demonstra um objeto inicialmente neutro, comercializado

\footnotetext{
${ }^{4}$ A "Solução Final" foi o plano estabelecido para a deportação de todos os judeus da Europa para os campos de extermínio, definido na Conferência de Wannsee, em janeiro de 1942 (United States Holocaust Memoriam Museum, [s.d]a)
} 
de forma comum na sociedade, que se associou a valores políticos e morais do plano nazista ao ter modificações demandadas.

Conclui-se, portanto, que a tecnologia tem o seu valor neutro até certo ponto, perdendo-o quando os objetos e sistemas tecnológicos são demandados e, a partir daí, incorporam o propósito político e moral do agente no seu desenvolvimento. O projeto nazista não permitiu a neutralidade da tecnologia: todas as ferramentas inovadoras eram imbuídas de valor, organizadas e operadas para servirem a um projeto de extermínio, indo além da tecnologia dada como neutra.

\section{O Holocausto como condutor do conceito do Genocídio}

O século XX despontou com a modernidade e desenvolvimento de tecnologias que entre outras coisas foram utilizadas em conflitos para fins de extermínio. Para empreender tal análise, o presente artigo analisará o Holocausto, caso juridicamente reconhecido como genocídio ${ }^{5}$, que ocorreu durante a Segunda Guerra Mundial. O uso dos campos civis de concentração, a intervenção de empresas privadas, campos de estudo, organização burocrática, entre outros, possibilitaram a relação entre a tecnologia e a violência direta, colocando a inovação, precedentemente um mecanismo de progresso, envolvida diretamente à aniquilação de um povo. Mas antes, é preciso entender e justificar o Holocausto como estudo de caso, à luz da teoria de genocídio.

O genocídio por definição vem a ser um massacre relacionado a um grande número de pessoas com uma motivação identitária, política, com vítimas em minoria, com menos poder e mais vulneráveis, sendo civis ou combatentes, e com o perpetuador podendo ser o Estado ou um grupo, que detém meios para massacrar ou aniquilar (Jones, 2011). Massacres que como forma de pressão psicológica mata culturas além de pessoas, o genocídio é um crime diferente de outros, por possuir aspectos jurídicos e se diferenciar pela intolerância que há no conflito com certos grupos, escolhendo-os matar por ser quem são.

O genocídio veio a ser classificado como crime diante da necessidade de mobilização universal por uma resposta pelas ações dos próprios nazistas, o que levou à criação do Tribunal de Nuremberg ${ }^{6}$ e posteriormente a Convenção Para a Prevenção e Repressão do Crime de Genocídio, onde foi definido o termo. Inicialmente, o termo genocídio foi apontado por Raphael Lemkin (apud Jones,

\footnotetext{
${ }^{5}$ Pela Convenção de 1948 das Nações Unidas.

${ }^{6}$ Tribunal internacional criado para julgar os altos cargos nazistas pelos crimes cometidos contra a humanidade durante a Segunda Guerra Mundial.
} 
2011, p.10) como um "um plano coordenado de diferentes ações para destruir as bases essenciais de um grupo", como a cultura e política que está presente por gerações, em um massacre que pode causar a desintegração desse todo. Com apoio e aprovação dos Estados Membros da ONU, foi definido em 1948:

Artigo II: Na presente Convenção, entende-se por genocídio os atos abaixo indicados, cometidos com a intenção de destruir, no todo ou em parte, um grupo nacional, étnico, racial ou religioso, tais como: a) Assassinato de membros do grupo; b) Atentado grave à integridade física e mental de membros do grupo; $\mathrm{c}$ ) Submissão deliberada do grupo a condições de existência que acarretarão a sua destruição física, total ou parcial; d) Medidas destinadas a impedir os nascimentos no seio do grupo; e) Transferência forçada das crianças do grupo para outro grupo (Brasil, 1952).

A partir desses elementos e da ocorrência do Holocausto emerge o estudo do genocídio. Na década de 70 iniciam-se os estudos comparativos, como o caso armênio e ucraniano, chegando a um maior interesse acadêmico a partir da década de 90, nos casos de Ruanda, Bósnia, Darfur, entre outros. Isso gerou uma interdisciplinaridade, como no campo da sociologia e antropologia, trazendo novas abordagens e expandindo os questionamentos sobre os limites e ambiguidades da Convenção de 1948, visando entender certos processos considerados como genocídio ou não. Hinton (2002) aponta que nada teria ocorrido sem o Holocausto: esse acontecimento foi catalisador, embora os casos com perfil e características de genocídio já acontecessem há décadas, sua conjuntura deu a maior visibilidade histórica.

Across a range of positions, the Holocaust sets the standard for what is considered unacceptable behaviour in international society and invokes the category of 'humanity' in a Eurocentric fashion by ignoring previous Western imperial genocides in the colonies (Barkawi \& Laffey, 2006, p. 340).

O genocídio perpetrado em colônias propiciou também o surgimento dos campos de concentração, demonstrando um primeiro exemplo de um inovador controle burocrático ao demarcar um espaço para domínio de um povo que ali era posto, formato que foi replicado para a Europa posteriormente. Aidan Forth (2017) esclarece que os campos são originários do Império Britânico durante a Segunda Guerra Anglo-Boer, na África do Sul, vinculando o colonialismo e a mobilização do controle totalitário de um povo, sendo campos que viriam a ser reutilizados pelos nazistas nas regiões da Polônia e Alemanha, na primeira metade do século $X X$.

Portanto, o genocídio não se encaixa em um processo inconsciente, mas sim numa escolha política consciente, que no caso nazista se tornou possível a 
partir da busca pela manutenção da pureza ariana no território europeu, feita por meio do extermínio de parte da população. Entre as partes constitutivas de um genocídio colocadas por Adam Jones (2011), os agentes, como grupos dominantes, se encaixam no caso do Holocausto, ao terem acesso ao poder de mobilização, aparatos tecnológicos, colocando em prática a sua intenção:

The Genocide of the European Jews 1933-45 was fundamentally indebted to the use of technology, and that technology was not a peripheral or secondary medium, but an absolutely essential medium for the execution of the so-called

"Final Solution" of the "Jewish Problem" (Leventhal, 1995).

A interdisciplinaridade do tema do genocídio trouxe espaço para o estudo no campo da antropologia, aprofundado por Hilton (2001), voltado a entender o ser humano em sua forma social e cultural localizado no tempo e espaço. Já na sociologia, Shaw (2010) é o autor que vê o macro do conflito, a relação indivíduo e sociedade, focando na democracia, direitos, como se organizam socialmente e como as instituições interagem, por meio da coleta de dados e análises gerais da população. Ou seja, essas diferentes abordagens têm em comum compreender os processos sociais e culturas que ocorrem durante o genocídio.

No âmbito da antropologia, existiu uma relação muito próxima com o Nazismo. Havia um interesse na época, em pesquisas, experimentos e tecnologias para aprimorar as teorias raciais, buscando legitimar os conhecimentos sobre a diferenciação de um povo frente à raça pura ariana, defendendo as evidências como estudos científicos. Hilton (2001) se depara com o estudo do genocídio ao olhar a miudeza e individualidade presente no conflito, entendendo o espaço local, os envolvidos e suas experiências que explicam a forma na qual tudo foi elaborado. O perfil do judeu é essencial para entender o tipo de violência perpetrada, por exemplo, por que se deu a escolha pelo extermínio por meio de campos de concentração e câmaras de gás. O objetivo primeiro era afastar esse grupo da sociedade dita civilizada e em seguida decidir pela melhor forma para aniquilar, o que está de acordo também com as percepções culturais e políticas dos idealizadores (Piper, 1994).

Já no campo da sociologia, Shaw (2010) elenca como contribuição principal para o entendimento do fenômeno do genocídio no Holocausto a sociologia da modernidade. No último século, iniciou-se um conjunto de processos que levariam a pensar as relações internacionais: como o Estado Moderno relacionado à formação do Estado-Nação abarcou o capitalismo e a industrialização, fatores capazes de fornecer condições materiais para se 
desenvolver em sociedade. $\mathrm{O}$ autor discute a existência de algo moderno no genocídio, o lado obscuro da modernidade utilizada para extermínio: em meio a um mito da busca pela civilização, buscam destruir o diferente à raça ariana, já que esse não poderia ser incorporado ao Estado-Nação, por atrapalhar o desenvolvimento e progresso da sociedade.

As práticas de crueldade e tortura modernas presentes no III Reich representaram a busca por exterminar em grande escala e em pouco tempo, alcançando um maior saldo quantitativo. Jones (2011) aponta como essa mudança social significa um fenômeno moderno, pois práticas de genocídio já aconteciam anteriormente, mas a modernidade permitiu saltos maiores, que resultam em grandes números de extermínio, uma maior eficiência sob o olhar nazista. Ou seja, resumidamente por Bauman (1998): a modernidade não é condição necessária, mas suficiente, para o acontecimento de um Holocausto.

Para Shaw (2010), há quatro mobilizações da modernidade que se relacionam ao genocídio: a primeira, o nacionalismo, que é o pertencimento a um grupo específico e a exclusão de outro que não deve estar na fronteira demarcada e pertencendo a estrutura organizacional - diante disso utilizam-se do poder soberano para destruir e assegurar essa territorialidade. Já o racismo científico é a segunda mobilização fundamental da modernidade, utilizado em discurso de poder e autoridade ao relacionar a ciência. Como mencionado anteriormente, no Holocausto o conceito de raça emergiu visando naturalizar a raça ariana como pura, separando-a do que era identificado como diferente, por meio de categorizações como a análise física dos indivíduos. A terceira mobilização se dá com a complexidade técnica e tecnológica permitidas pela modernidade, e que serão desenvolvidas adiante. Os campos de concentração, ferrovias, câmaras de gás, experimentos científicos, máquinas IBM - tudo isso mobilizado por meio de um desenho racional e a favor de um projeto que tinha como objetivo fim o EstadoNação ideal. Por fim, a quarta e mais discutida por Bauman (1998) é a burocracia da morte, facilitada pelos tempos modernos: as tarefas eram altamente especializadas e as performances coordenadas, contando com operações mecânicas, objetivas e automatizadas, que contribuíam para o extermínio.

Todos esses pontos permitidos pela modernidade geraram saldo quantitativo de mortes e um distanciamento profundo, pois não estavam somente "apertando um botão" de forma operacional, mas ligando uma câmara de gás. Todas essas pequenas funções técnicas seguindo uma organização burocrática resultavam no propósito final, que não necessariamente era visível. Ali tinham perpetradores indiretos, o que torna difícil provar se havia a intencionalidade. 
Sem esses elementos, o genocídio nazista poderia ter sido implementado da mesma forma? A questão é que a modernidade não causa o genocídio, nem todo genocídio está necessariamente atrelado a esse padrão, mas possui funções facilitadoras. Ou seja, a modernidade mudou os padrões do genocídio, tal como mudou os da guerra, mas nem por isso o genocídio é produto da modernidade. Como aponta Bauman (1998), o genocídio é facilitado por tal.

\section{Subsidiárias alemães surgindo em tempos de extermínio}

A perseguição dos nazistas aos judeus foi controlada, acelerada e eficiente, tudo isso possibilitado pela customização da Dehomag, subsidiária alemã da IBM. Era possível projetar e executar sistemas que identificassem, classificassem e quantificassem a população ariana, separando-a dos judeus. Black (2002), em IBM and the Holocaust, The Strategic Alliance Between Nazi Germany and America's Most Powerful Corporation, permite que seja entendido como a empresa americana conquistou o intelecto alemão, dando assistência com o desenvolvimento de uma Hollerith Machine, o sistema de tabulação customizado da IBM.

Como aponta o autor, o nazismo abriu caminho para que os cientistas alemães encontrassem maneiras de utilizar suas qualificações e capacidades para modificar a ciência. Entre os intelectuais em defesa da política planejada por Adolf Hitler estavam os estatísticos, em escritórios e departamentos de censos sendo os primeiros clientes da subsidiária alemã (Black, 2011). Eles visavam produzir uma ciência evoluída, ultrapassando tudo que já existia na época de controle burocrático de um povo. Para isso, dependiam das inovações desenvolvidas nos cartões perfurados e na tecnologia de tabulação da IBM. Somente Dehomag poderia produzir um sistema para controlar a população judia.

Hitler era favorável às estatísticas, ao conhecimento útil, exigindo não apenas pessoas que servissem ao seu governo, como bem fossem científicos, capazes de desenvolver métricas e estudos acerca do projeto nazista, como aponta Black (2011). Allgemeines Statistisches Archivs (ASA) era o jornal oficial da Sociedade Estatística Alemã, como apresentado pelo site German Statistical Society $^{7}$, no qual mostra como o papel dos estatísticos era essencial para alimentar a hierarquia nazista e a capacidade de superioridade desses em

\footnotetext{
7 Todas as edições anteriores podem ser acessadas pelo link referenciado: Deutsche Statistische Gesellschaft, 2019.
} 
produzir conteúdo: uma forma de estudiosos do campo de estatísticas de qualquer lugar do mundo conseguir entender os resultados alemães, sobre a metodologia comprovada que identificava os judeus detalhadamente como indesejáveis. Em muitos casos, os artigos foram escritos em conjunto com especialistas da Dehomag, descrevendo o trabalho técnico dos equipamentos específicos da subsidiária aplicado às práticas, política e programas do Reich, como menciona o Black (2011).

Black (2011) cita uma edição do jornal de 1934, em que o médico Prof. Dr. Johannes Müller declara "remember that several very important problems are being tackled currently, problems of an ideological nature. One of those problems is race politics, and this problem must be viewed in a statistical light". A raça não ariana era vista como um problema que deveria ser monitorado por meio do rastreamento e análise, não apenas da filiação religiosa como judeus, mas considerando também a ancestralidade. Tudo isso em busca da pureza da raça de toda a Europa.

Esse problema colocado viria a ser discutido na época, já que para outro médico, Dr. Karl Keller, os judeus não eram uma raça, mas uma mistura de várias. Assim, era pedido aos médicos que examinassem a população em busca de características raciais registrando fielmente as informações, com um treinamento que tentavam implementar para entenderem os ancestrais dessas pessoas e reconhecer a sua origem de maneira confiável, como coloca Black (2011).

A única forma que encontraram de não deixar escapar qualquer erro era registrar toda a população, o que seria feito com o estabelecimento de informações biográficas pessoais para que pudessem ser usadas para os cientistas. Essa estratégia permitia que as estatísticas alemãs fossem testemunhas registradoras e conspiradoras dos facilitadores e executores da política de Hitler, ao trabalharem próximos em parceria, o que era liderado fortemente pelo Gabinete de Política Racial do Partido Nazista, com apoio de outras agências internas da própria $S^{8}$ (Black, 2011). Identificar os judeus foi apenas o início da busca pela destruição por completo desses no território alemão.

Nenhuma das declarações iniciais sobre o que era o projeto nazista inibiu a subsidiária da IBM a continuar colaborando e prestando serviços de alto nível ao III Reich. O método da IBM, como aponta Black (2002), era antecipar as necessidades das agências governamentais, projetando soluções com o uso dos dados que tinham sido capturados até então, aprimorando como utiliza-los e

\footnotetext{
${ }^{8}$ Abreviação de Schutzstaffel, a organização paramilitar ligada ao partido nazista.
} 
identificando cada vez mais dali em diante, podendo implementar programas até mesmo além da tabulação quando solicitado.

Cada sistema Hollerith tinha que ser projetado de forma única pelos engenheiros da Dehomag, assim como a produção feita dos sistemas de inventário das muitas peças de aeronaves para a Luftwaffe $^{9}$. As máquinas da IBM por si só não significariam nada, os tabuladores e cartões não foram entregues prontos para uso como máquinas de escrever (Black, 2011). Além da logística dos horários das ferrovias para Reichsbahn, contribuíram principalmente, com registro da população dos judeus para o Escritório de Estatística do Reich, tabuladores projetados para serem completamente diferentes entre si.

Cada cartão era personalizado com campos, colunas de dados, trazendo uma precisão para os leitores que entendiam o que cada buraco perfurado significava em seu lugar. Os funcionários do Reich precisavam receber treinamento para utilizá-los, a subsidiária da IBM Dehomag precisava entender os detalhes mais minuciosos para o que seria utilizado pela política nazista, para projetar os cartões e criar códigos indissociáveis. Por causa das necessidades quase ilimitadas de tabuladores no conflito racial e geopolítico do líder Hitler, a IBM de Nova lorque reagiu com entusiasmo às perspectivas do nazismo. Apenas algumas semanas depois de Hitler chegar ao poder, a IBM de Nova lorque investiu mais de sete milhões de marcos do Reich - o que seria mais de um milhão de dólares hoje - para expandir a capacidade da subsidiária alemã de fabricar máquinas. Enquanto empresários americanos estavam apavorados e ofendidos com a política alemã e restringindo e cancelando qualquer negócio na Alemanha, Thomas J. Watson, CEO da IBM na época, se aventurou em uma expansão inédita da Dehomag (Black, 2011).

A IBM hoje se envolve nos processos de outras empresas, desempenhando um papel de torná-los mais inteligente com a plataforma Watson de serviços cognitivos $^{10}$ que carrega o nome do antigo CEO, sendo a maior inteligência artificial projetada pela IBM, que integra os fluxos de trabalho e oferece os serviços de inteligência artificial quando e onde for preciso. Tal sistema permitiu a IBM se tornar uma empresa de ponta e referência global na inteligência artificial, mas que possui traços de uma ferramenta de coleta de informações que oportunizou o aprimoramento do plano de extermínio dos judeus no território da Europa.

\footnotetext{
${ }^{9}$ Força aérea armada da época do nazismo.

$10 \mathrm{O}$ acesso ao site e a mais informações podem ser feitos no link referenciado: IBM, [s.d].
} 
O que foi desenvolvido de forma customizada para o partido nazista no século XX demonstra como a tecnologia ao ser demandada foi instrumentalizada em valores e políticas decisivas e eliminatórias que possibilitaram o Holocausto. Era associado a uma benção divina o surgimento dessa empresa com tamanha capacidade para imbuir o III Reich com informação da população, principalmente aquela que era vista como ameaça à pureza ariana (Black, 2002). Tudo isso era o alinhamento como um todo da IBM e os cientistas nazistas na busca pelas estatísticas populacionais, que tinham como promessa erradicar os doentes e segmentos inferiores da sociedade. A metáfora trazida no livro de Black (2002) era a comparação entre a dissecação de corpos feita por médicos alemães e a dissecação dos alemães como um todo por Dehomag, que relataria todas as características individuais em um pequeno cartão, permitindo que as máquinas de tabulação fossem capazes de calcular e classificar todos daquele território.

Leventhal (1995) em seu texto traz a imagem de uma máquina Hollerith que está localizada no Museu Memorial do Holocausto dos Estados Unidos (Washington, DC) e disponível para visitação mediante agendamento ${ }^{11}$.

Figura 1: The Hollerith Machine Produced by Dehomag

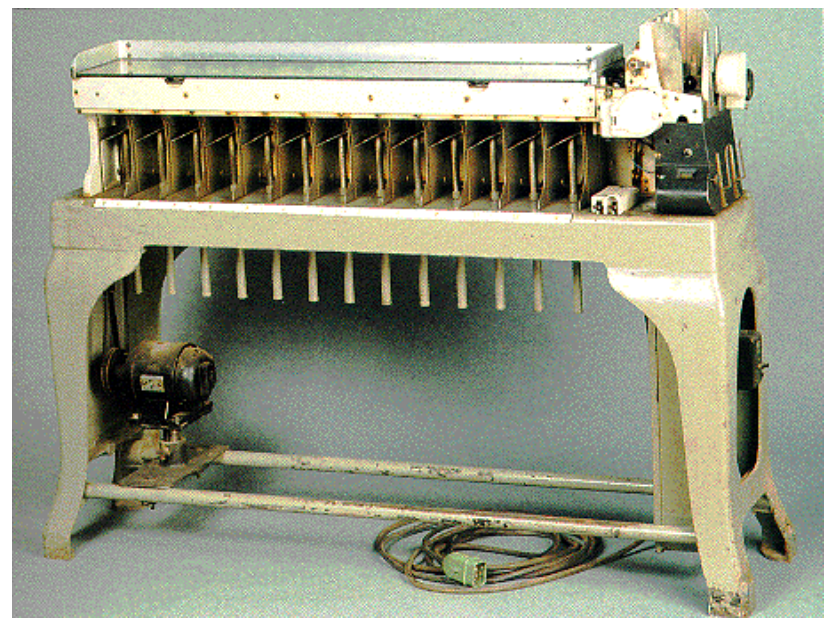

Fonte: Leventhal, 1995.

A ferramenta foi um dos mecanismos pelos quais os nazistas foram capazes de rastrear as populações judaicas e acumular informações sobre o "sucesso" do genocídio, conforme coloca o autor Goeffrey Austrian (1982), para quem o genocídio dos judeus de 1933 a 1945 foi fundamentalmente refém do uso da tecnologia.

\footnotetext{
11 Conforme informado no site do Museu, cujo link está referenciado: United States Holocaust Memoriam Museum, [s.d.]b.
} 
Outro exemplo é o papel da I.G. Farben junto com outras empresas industriais na pesquisa e desenvolvimento do gás Zyklon $B$ e na formação de locais de trabalho escravo em campos de concentração (Borkin, 1978). Durante os Julgamentos de Nuremberg, I.G. Farben, um dos maiores conglomerados químicos do mundo na época, foi acusado de crimes contra a paz ${ }^{12}$, apropriação de territórios ocupados e colaboração com os crimes da SS, por meio do uso extensivo de mão de obra escrava. É de conhecimento que uma subsidiária da I.G. Farben produziu o mortal gás Zyklon B já mencionado e utilizado nas câmaras de gás de Auschwitz, por meio de uma fábrica/laboratório construída e operada pela empresa, em Buna, campo de trabalho forçado em Auschwitz. A empresa contribuiu com os estatutos do Campo de Extermínio no tratamento de prisioneiros: se um trabalhador era considerado desobediente ou fraco, era entregue à SS, e na maioria dos casos, brutalmente punido ou assassinado, como aponta Borkin (1978).

I.G. Farben não fora considerada culpada por produzir o gás com a intenção de cometer genocídio, pois a alegação é que teriam sido informados que a encomenda era para tratamento de piolhos, como indicado por Leventhal (1995). O envolvimento dos funcionários da I.G. Farben ainda é uma questão em aberto, e embora não esteja claro até que ponto exatamente a I.G. Farben realmente participou do genocídio, conduziu experimentos utilizando seres humanos, como drogas contra tifo, doença transmitida por parasita nos corpos, pílulas para dormir e gás venenoso para os nervos (Leventhal, 1995), tudo isso administrado sob a proteção da I.G. Farben. Sob o regime nazista, a ciência e a medicina eram focadas nos próprios cientistas e não na instituição da ciência. Como exemplo se tem:

Robert Jay Lifton's The Nazi Doctors has shown the complicity of the entire field of medical science in the design, planning and execution of medical experiments utilizing human beings in often horrifying and brutally painful experimentation. It is above all the bio-medical sciences that were useful to the Nazis in carrying out experiments on human subjects that were deemed to be extremely dangerous or painful (Leventhal, 1995).

Embora convincente, esse trabalho demonstra como houve outras formas de abuso e tortura humana, possibilitado por organizações, instituições e aparatos burocráticos, departamentos acadêmicos demandados pelo Estado Nazista, para a realização e idealização do extermínio, como aponta o autor (Leventhal, 1995).

\footnotetext{
12“[...] definition of the crime against peace covers not only wars of aggression and wars in contravention of treaties, agreements and assurances, but also 'invasions of other countries"' (Clark, 2007).
} 
A participação de ambas as subsidiárias alemãs demonstram como a tecnologia foi instrumentalizada pelos valores e práticas políticas com propósito definido. É perigoso imaginar como intervenções privadas tornaram possível a busca pela aniquilação de um grupo, ao auxiliar em métodos de controle, como o caso da IBM, e no extermínio direto por meio de um gás desenvolvido pela I.G. Farben para matar em um curto espaço de tempo. Tudo isso de forma burocraticamente organizada, considerando até mesmo a preocupação de que outros prisioneiros não percebessem o que ali estava ocorrendo.

\section{Burocracia}

Inovações puderam e, ainda hoje, podem ser utilizadas como impulsionadoras do desenvolvimento de uma sociedade. Porém, foram colocadas como mecanismos para a morte, com meios introduzidos em táticas genocidas. $\mathrm{O}$ desenvolvimento de novas tecnologias foi essencial e orquestrado por fazer parte do plano do genocídio nazista que se tornou possível pela organização em todos os aspectos. As formas planejadas para que esse feito ocorresse foram transformadoras na busca por "alcançar o máximo resultado com o mínimo de esforços e custos", como aponta o autor Bauman (1998, p. 176).

Uma das questões centrais da tecnologia é afastar o envolvimento humano das tarefas. No caso de extermínio, de fato algumas pessoas estiveram envolvidas sem perceber a atrocidade que estava sendo planejada dentro dos escritórios. Porém, outras ajudaram a perpetrar, buscaram desenvolver tecnologias e outras ferramentas para aprimorar os serviços, por meio de uma organização burocrática, cientes do envolvimento com o SS:

\footnotetext{
A maioria dos que executaram o genocídio eram pessoas normais, que passariam facilmente em qualquer peneira psiquiátrica conhecida, por mais densa e moralmente perturbadora. Isso também é teoricamente intrigante, em especial quando visto em conjunto com a "normalidade" daquelas estruturas da organização que coordenaram as ações desses indivíduos normais no empreendimento do genocídio. Já sabemos que as instituições responsáveis pelo Holocausto, mesmo se consideradas criminosas, não eram, em nenhum sentido sociologicamente legítimo, patológicas ou anormais. Agora vemos que as pessoas cujas ações elas institucionalizaram também não se desviavam dos padrões estabelecidos da normalidade (Bauman, 1998, p. 39).
}

Everett C. Hughes (1962), autor de Good People and Dirty Work, mencionado no livro de Zygmunt Bauman (1998), aprofunda sobre a indiferença moral de perpetradores que estavam trabalhando nos campos de concentração, e como dali, poucas pessoas que inicialmente eram consideradas cruéis na 
região, se revelaram em suas ações. Como exemplo prático, apresento adiante material resultado de uma visita ao campo de Sachsenhausen, o mais próximo de Berlim na Alemanha, realizada em 2019.

O governo alemão perpetrou um trabalho cruel no último século. Os crimes não precisam ser citados, mas é válido reconhecer os indivíduos que participaram de forma direta ou indireta nos campos de concentração, por meio da humilhação, trabalho forçado, abuso físico, psicológico, com artifícios usados sistematicamente em nome da superioridade e pureza racial. "How could these millions of ordinary people live in the midst of such cruelty and murder without a general uprising against it and against the people who did it?" (Hughes, 1962, p. 4).

A questão a ser colocada é sobre as pessoas que fizeram o trabalho no meio de uma política nazista, bem como as que assistiram e conviviam com esses perpetradores. Antes do regime de Hitler, segundo Hughes (1962), o ódio entre os grupos não existia dessa forma, casamentos entre arianos e judeus aconteciam. A questão racial dentro de clubes, escolas e hotéis era muito menos evidente do que quando colocada de forma descarada pelo governo nazista. A posição que Hitler se colocou perante os judeus influenciou e cooptou muitas pessoas para o seu projeto.

A organização burocrática dentro do comando SS fez com que as pessoas mantivessem em silêncio o que estava sendo perpetrado diante do resto da sociedade e até mesmo dos seus familiares, com receio da reputação que teriam e das discussões que poderiam ser abertas. Quem tinha conhecimento e presenciava ou cometia atrocidades nos campos, estava diante de uma indiferença moral frente ao extermínio. É difícil dimensionar o quanto essas pessoas estariam envolvidas no extermínio e, na ocasião, a naturalidade com a qual se falava sobre estar alistado para servir ao exército.

Porém, em uma perspectiva realista, as pessoas comuns do território sabiam que os campos existiam, sabiam e viam vítimas serem raptadas e desaparecerem, sendo transportadas em trens, ou indo trabalhar em fábricas próximas aos campos e não retornando, ou ainda conheciam quem estava levando essas pessoas para o Estado nazista. Os detalhes da logística e do serviço dentro dos campos eram mantidos em segredo, mas as pessoas que tinham ciência, não conseguiam ou não mesmo queriam se posicionar contra. $O$ segredo era cultivado e suportado pelo medo e pelo terror (Hughes, 1962).

Atualmente museu, o antigo campo de concentração Sachsenhausen, localizado em Oranienburg, a 40km de Berlim, possui diversos materiais sobre os perpetradores que ali estiveram: pessoas consideras normais que se associaram 
a um projeto de extermínio. Entre as bibliografias expostas sobre a vida e função dos perpetrados, abaixo a figura mostra um deles que trabalhou no campo citado: Johann Nowacki, conhecido como um dos mais cruéis pelo seu nível de brutalidade e por perseguir os prisioneiros nas noites. Ele maltratava os constantemente e foi convidado para atuar no campo juntando-se ao SS Death's Head units.

"The SS men would chase all the inmates of a block into the sleeping quarters of their respective barracks and have them 'do exercises' with the Windows closed. Many prisioners did not survive this treatment"13. Um ano após estar no campo, ele foi promovido para supervisionar os líderes e era premiado pela sua nata liderança.

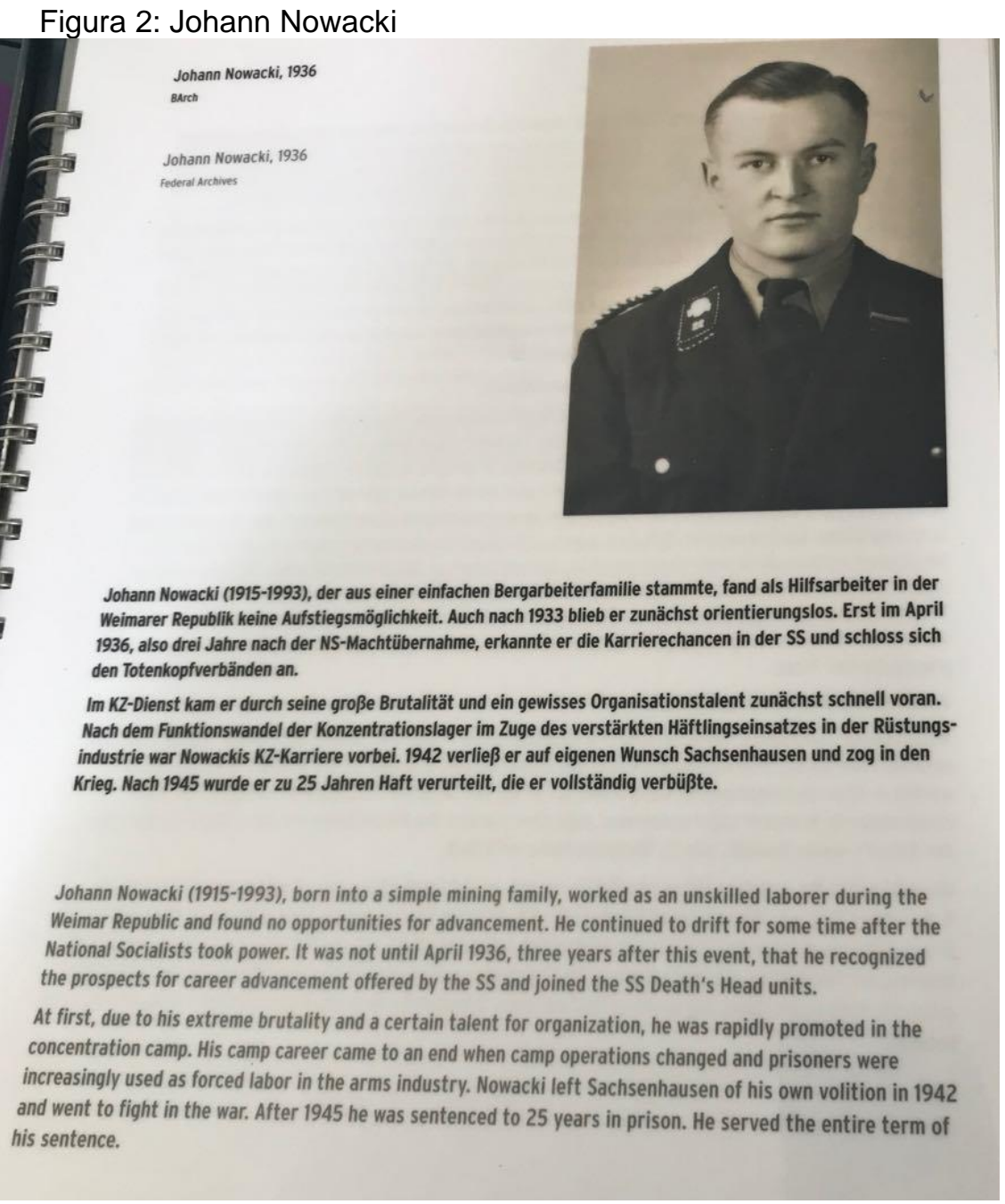

Fonte: Acervo próprio.

\footnotetext{
${ }^{13}$ Parte retirada da bibliografia física exposta no local.
} 
O exemplo acima demonstra um indivíduo vindo de família simples e que trabalhava em outro setor, mas vira no projeto nazista uma oportunidade para alavancar sua carreira, se renovar e aprofundar suas habilidades pessoais para servir a unidade. Diante de um prospecto de tecnologia que estava inserido na organização burocrática, a participação humana direta no conflito intensificou e tornou possível que o extermínio em massa fosse perpetrado, perdendo qualquer neutralidade e foco somente no trabalho, mas fazendo parte individualmente do que estava sendo planejado, de forma consentida ou visando somente o seu crescimento profissional.

Para considerar o trabalho que foi feito durante o tempo do projeto nazista, é preciso pensar nessas pessoas que estavam diretamente envolvidas, como os membros da SS que operavam nos campos de concentração, os nazistas que chegaram ao poder desempenhando organizações de um Estado, todos esses sendo instrumentos de um propósito.

Orders from the central offices of the S.S. were couched in equivocal terms as a hedge against a possible day of judgment. When it became clear that such a day of judgment would come, the hedging and intrigue became greater; the urge to murder also became greater, because every prisoner became a potential witness (Hughes, 1962, p. 10)

Alguns tiveram a sua personalidade corrompida inclinando-se para ações que eram propostas, outros já possuíam uma índole inclinada à crueldade e escolheram se associar, atraídas pelo projeto. O poder e a disciplina da SS tornaram-se tão relevantes, que quem entrasse só sairia dali pelo suicídio, morte ou com problemas mentais, como trazido pelo autor (Hughes, 1962).

\section{Conclusão}

Atualmente, a tecnologia perdeu o seu valor neutro, mas está sendo aplicada em nome da defesa dos Direitos Humanos, o que significa que tem sido desenvolvida para prevenção e contenção das atrocidades em massa, por meio da utilização de ferramentas que visam prever, mitigar, responder ou documentar as atrocidades, com técnicas que incluem a tecnologia da informação e comunicação (ICT), como celulares, mídias sociais, mapeamentos de crises, imagens de satélites, entre outras, conforme aponta o autor Tuckwood (2004). Muitas vezes, o desenvolvimento dessas tecnologias parte de iniciativas privadas, que se posicionam diante da ineficácia de atuação dos Estados e Organizações Internacionais frente ao dever de proteger. 
A tecnologia hoje é colocada como essencial, na forma que as pessoas trabalham, aprendem, se comunicam, socializam e se organizam. Nas relações internacionais, o desenvolvimento tecnológico tem conduzido mudanças estruturais. $O$ campo dos Direitos Humanos se beneficia da atuação de atores não estatais que se aprofundam na análise de dados sobre conflitos e atrocidades em andamento, que se colocam diante da atuação de Estados e Organizações Internacionais. Alguns dos crimes ocorridos no Holocausto continuam sendo perpetrados de alguma forma até hoje, em uma escala com futuro imprevisível, mas é preciso estar preparado para reagir frente a isso. A tecnologia é um grande fator para a prevenção, aviso e mitigação dos impactos das atrocidades que estão a ocorrer, como, por exemplo, a ferramenta crisis mapping, - (que permite interpretar os dados e pode ser utilizada para direcionar os recursos e dar assistência a pessoas em situações de risco), que conseguiu apresentar uma visualização geográfica do território da Síria identificando violações de direitos humanos durante a guerra civil (Tuckwood, 2004).

O autor traz a comunicação e coleta de dados como estratégia utilizada por atores relevantes, por meio de ferramentas como crowsourcing, crowdseeding ou data mining, web mining, métodos para a reunião de dados que observam as atividades online (Tuckwood, 2004). A tendência é que as tecnologias sejam cada vez mais baratas, úteis e acessíveis respondendo a atrocidades em massa, com o uso assertivo de aeronaves, rádios no aprimoramento da observação de regiões que estão em iminência de conflito.

Tem-se o contraponto, portanto, do impacto e uso negativo que a tecnologia teve durante o século $X X$ nos conflitos e a busca pela mudança no cenário atual. Durante a Segunda Guerra Mundial, o Holocausto deu origem ao conceito de genocídio e foi cenário de como empresas, pessoas e líderes se envolveram no uso da tecnologia por meio de uma organização burocrática, intensificando a política de extermínio - mecanismos de uma sociedade moderna atuantes que facilitaram a aniquilação em massa.

Genocídios ocorreram no último século, porém, diante de uma perspectiva inicialmente colocada como neutra. Com as evidências aqui postas, em pesquisa futura pretende-se expandir os avanços tecnológicos desenvolvidos desde o Holocausto, considerando outros casos de genocídio, como o de Ruanda, em que houve a influência das mídias na política de extermínio, colocando de forma comparativa ao que tem sido desenvolvido em tecnologia hoje, sobre a égide da segurança internacional. Articulando essas questões, perceber-se-á como os 
interesses mudaram e mudam a forma de utilização da tecnologia - seja de modo mortal, seja de maneira disciplinar, ou para contribuir na prevenção de fatalidades.

\section{Referências Bibliográficas}

ALLEN, Michael T.. The Business of Genocide: The SS, Slave Labor, and the Concentration Camps. Chapel Hill, NC: University of North Carolina Press, 2002.

AUSTRIAN, Goeffrey D.. Herman Hollerith: Forgotten Giant of Information Processing. New York: Columbia University Press, 1982.

BARKAWI, Tarak; LAFFEY, Mark. The Postcolonial Moment in Security Studies. Review of International Studies, vol. 32, n. 2, abr. 2006, pp. 328-352.

BAUMAN, Zygmunt. Modernidade e Holocausto. Tradução Marcus Penchel. Rio de Janeiro: Jorge Zahar, 1998.

BLACK, Edwin. How IBM Technology Jump Started the Holocaust. Gizmodo, 16 jun. 2011. Disponível em <https://gizmodo.com/how-ibm-technology-jump-startedthe-holocaust-5812025>. Acesso em: 12 out. 2019.

BLACK, Edwin. The IBM and the Holocaust: The Strategic Alliance Between Nazi Germany and America's Most Powerful Corporation. New York: Three Rivers Press, 2002.

BORKIN, Joseph. The Crime and Punishment of I.G. Farben. New York: Free Press, 1978.

BRASIL. Decreto no $\mathbf{3 0 . 8 2 2}$, de 6 de maio de 1952. Promulga a convenção para a prevenção e a repressão do crime de Genocídio, concluída em Paris, a 11 de dezembro de 1948, por ocasião da III Sessão da Assembléia Geral das Nações Unidas. Brasília, DF: Presidência da República, 6 mai. 1952. Disponível em: < http://www.planalto.gov.br/ccivil 03/Atos/decretos/1952/D30822.html>. Acesso em: 19 abr. 2020.

CLARK, Roger S. Nuremberg and the Crime Against Peace. Washington University Global Studies Law Review, vol. 6, n. 3, 2007, p. 527-550. Disponível em: <https://openscholarship.wustl.edu/law_globalstudies/vol6/iss3/6>. Acesso em: 01 dez. 2019.

DEUTSCHE STATISTISCHE GESELLSCHAFT. Entwicklung des Allgemeinen Statistischen Archivs: 1890 - 2008. Frankfurt: Deutsche Statistische Gesellschaft, 2019. Disponível em: <https://dstatg.de/publikationen/entwicklungdes-allgemeinen-statistischen-archivs-1890-2008>. Acesso em: 19 abr. 2020.

FORTH, Aidan. Barbed-Wire Imperialism: Britain's Empire of Camps, 18761903. Oakland, California: University of California Press, Berkeley series in British studies, vol. 12, 2017.

FRIEDMAN, Thomas. The World is Flat: A Brief History of the Twenty-first Century. Londres: Penguin Books, 2005, cap 5. 
HINTON, Alexander L.. The Dark side of Modernity: Toward and Athropology of Genocide In: HINTON, Alexander L.. Annihilating Difference: The Anthropology of Genocide. Berkeley and Los Angeles, California: University of California Press, 2002, p. 1-40.

HUGHES, Everett C.. Good People and Dirty Work. Social Problems, vol. 10, n. 1, 1962, $\quad$ p. 3-11. Disponível em: <https://www.jstor.org/stable/799402?seq=1\#page_scan_tab_contents $>$. Acesso em: 12 out. 2019.

IBM. Watson. [S.I.]: [s.d.]. Disponível em <https://www.ibm.com/watson/br-pt/> Acesso em 03 dez. 2019.

JONES, Adam. Genocide: A Comprehensive Introduction. 2a ed.. Nova York: Routledge, 2011, cap.1.

KATZ, Eric. On the neutrality of technology: the Holocaust death camps as a counter-example. Journal of Genocide Research, vol. 7, n. 3, 2005, p. 409-421. Disponível em: <https://www.tandfonline.com/doi/abs/10.1080/14623520500190363>. Acesso em: 02 dez. 2019.

LEVENTHAL, Robert S.. Information and Technology in the Holocaust. [S.I.], 1995. Disponível em <http://www2.iath.virginia.edu/holocaust/infotech.html>. Acesso em: 28 nov. 2019.

ORGANIZAÇÃO DAS NAÇÕES UNIDAS [ONU]. Declaração Universal dos Direitos Humanos. Palais de Chaillot, Paris: Assembleia Geral das Nações Unidas, $\quad 10 \quad$ dez. $1948 . \quad$ Disponível em <https://www.ohchr.org/EN/UDHR/Pages/Language.aspx?LanglD=por>. Acesso em: 10 out. 2019.

PIPER, Franciszek. Gas chambers and crematoria. In Yisrael Gutman and Michael Berenbaum, eds. Anatomy of the Auschwitz Death Camp. Bloomington, IN: Indiana University Press, 1994, p. 157-182.

PRESSAC, Jean-Claude; VAN PELT, Robert-Jan. The machinery of mass murder at Auschwitz. In: GUTMAN, Yisrael Gutman; BERENBAUM, Michael (Eds). Anatomy of the Auschwitz Death Camp. Bloomington, IN: Indiana University Press, 1998, p. 183-245.

SHAW, Martin. Sociology and Genocide. In: BLOXHAM, Donald; MOSES, A. Dirk (Eds.) The Oxford Handbook of Genocide Studies. Oxford: Oxford University Press, 2010, cap. 7.

TUCKWOOD, Christopher. The State of the Field: Technology for Atrocity Response. Genocide Studies and Prevention: An International Journal, vol. 8, n. 3, 2014, p. 81-86.

UNITED STATES HOLOCAUST MEMORIAM MUSEUM. A "Solução Final". Washington, D.C.: Holocaust Encyclopedia, [s.d.]a. Disponivel em $<$ https://encyclopedia.ushmm.org/content/pt-br/article/the-final-solution>. Acesso em: 12 out. 2019. 
UNITED STATES HOLOCAUST MEMORIAM MUSEUM. Dehomag D11 sorter. Washington, D.C.: United States Holocaust Memorial Museum Collection, Gift of the Technische Sammlungen Dresden, [s.d.]b. Disponivel em <https://collections.ushmm.org/search/catalog/irn521587>. Acesso em: 18 abr. 2020.

UNITED STATES HOLOCAUST MEMORIAM MUSEUM. O que é Genocídio. Washington, D.C.: Holocaust Encyclopedia, [s.d.]c. Disponivel em $<$ https://encyclopedia.ushmm.org/content/pt-br/article/what-is-genocide>. Acesso em: 20 abr. 2020.

WINNER, Langdon. The Whale and the Reactor: A Search for Limits in an Age of High Technology. Chicago, IL: University of Chicago Press, 1986. 